\title{
Moral Behaviour And Ethical Misconduct In Nigerian Small Businesses
}

Johannes A. Wiid, University of South Africa (UNISA), South Africa

Michael C. Cant, University of South Africa (UNISA), South Africa

Claudette van Niekerk, University of South Africa (UNISA), South Africa

\begin{abstract}
The small business sector plays a vital role in the economic development, upliftment and job creation of any third world country, and even more so in Africa. Small and Medium Enterprises (SME's) have underperformed over the past years and therefore have not contributed their expected roles in the growth and development of the Nigerian economy. This can and may lead to unethical behaviour and questionable practices which speak of moral decay - something that Africa, in general, and Nigeria, specifically, has been accused of. The performance and ethical behaviour of Nigerian SMEs have been of great concern to numerous individuals, parties and organisations (Onugu, 2005:8). Since managers' decisions impact organisational goals and behaviours, this research aims to determine whether a sense of moral behaviour will have an influence on the concern for ethical misconduct in the Nigerian business environment by examining the relationship between "Moral Behaviour" and the "Concern for Ethical Dilemmas/Misconduct". The research followed a quantitative approach. Results indicated that there is a fine line between what is perceived as being morally wrong or unethical and that, in many instances, the focus is rather on future existence of the business and not really on the ethical issues involved. The study confirms that there is a medium to strong relationship correlation between sense of ethical concerns and immoral behaviour in the Nigerian small business environment. The hypothesis $\left(H_{0}\right.$ : Entrepreneurs who have an acute sense of moral behaviour are concerned about ethical misconduct/dilemmas in the business environment) is therefore accepted.
\end{abstract}

Keywords: Moral Behaviour; Ethics; Ethical Misconduct; Dilemmas; Nigeria; SMEs; Entrepreneurs

\section{INTRODUCTION}

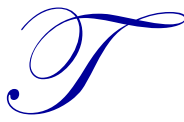

here has been a strong focus on ethical behaviour and morality in many organisations since the collapse of the major banks in Europe during 2008 and, consequently, the uncovering of major corruption in organisations worldwide. This has led to governments, private sector, and even individuals to call for stronger regulations and control of business practices in order to stamp out, or at least reduce, instances of morally and ethically questionable practices. Operating in the complex business environment of today, it has become very challenging for many businesses to survive, let alone to be profitable. However, this pressure can impact on the practices employed by organisations and in the way they conduct business in order to survive. In other words, their concern for behaving in an ethical manner may be effected, and as businesses battle to make a profit and gain a competitive advantage, an increased level of unethical behaviour in the business environment will probably occur. SMEs in particular, are not exempt from this situation and, in many cases, will be more prone to this type of behaviour than larger organisations. This may be due to the fact that they are of the opinion that such actions are less serious in the case of a smaller business than in the case of a larger one.

The small business sector has a vital role to play in the growth and development of any country, and maybe more so in third world countries, and has become the principal element of job creation in many countries where, in some cases, up to $80 \%$ of employment is vested in small businesses (Valadez, 2011:1). Subsequently, the development and growth of SMEs in Nigerian small businesses hold meticulous significance for imminent entrepreneurs (Ogundele, Hassen, Idris, Adebakin \& Iyiegbuniwe, 2010:5). It has been noted that one of the biggest 
social and economic struggles in Nigeria, as well as in the rest of Africa, which is in need of urgent attention and action, is the moral decay taking place, a lack of social responsibility, and the universal politeness among humanity, and evidently business ethics (Ogundele et al., 2010:5). In Nigeria, there is a prevalent shortage of commitment to ethical behaviour in the small business environment, which is alarming as a result of its extent (Ogundele et al., 2010:5). Since 1997, and even up to today, Nigeria has been dubbed as one of the most fraudulent and corrupt countries in the world. In fact, in 2001, Nigeria was listed second only to Bangladesh, as the most corrupt and fraudulent country in the world - which is a dubious honour indeed (Ogundele et al., 2010:5).

This study, which focuses on moral and ethical behaviour in SME's in Nigeria, attempts to establish whether these businesses have a sense of moral behaviour and to what extent it influences these businesses' concerns for ethical misconduct. The literature will focus on business ethics, moral behaviour in the business environment, as well as the link between a sense of moral behaviour and ethical misconduct. In the subsequent section of this paper, the objectives and research methodology will be discussed, followed by the research findings, recommendations, and concluding remarks.

\section{ETHICAL BEHAVIOUR IN THE BUSINESS ENVIRONMENT}

Operating in a complex business environment, as we find today, can be challenging and stressful for businesses to survive, but more so in the case of SMEs. These challenges may negatively affect the way SMEs conduct business in order to be profitable; in other words, the survival of the business is more important than their concern for ethical misconduct. Mahdavi (2009:2) observed that, with the expansion of a global business perspective as a result of new technologies and developments in cyber marketing and e-commerce activities, the study of business ethics has become exponentially more important, mainly due to the increase in ethical and social responsibility.

The ethical environment is a relatively new sub-discipline with the intention to rationalise moral motivations and beliefs for the purpose of environmental protection (Raisner, 1997:1331; Yang, 2006:23). Ethics, according to Mujtaba (2005:1), is the branch of philosophy that theoretically, rationally, and reasonably determines right from wrong, good from bad, moral from immoral, and fair from unfair actions and behaviour. Okafor (2011:34) states that the role of ethics is the principle of morality; it is both the science of the good and the nature of the right. "Ethics is a system of moral principles or rules of behaviour which involves doing the right thing in the right manner" (Okafor, 2011:34). In general, ethics create the rules and standards that manage the moral behaviour of individuals and groups. It involves sincere selflessness to core motives, to probable prospective of impairment, and to congruency with reputable values and rules (Mujtaba, 2005:1). Ethics are therefore "... moral guidelines which govern good behaviour..."; in other words, behaving ethically is doing what is morally right (Okafor, 2011:34; Riley, 2012:1).

There are a number of benefits and advantages to organisations that conduct their business in an ethically acceptable way. For example, ethical behaviour might ${ }^{1}$ :

- $\quad$ have a positive effect on an organisation's sales and profits because customers are more inclined to support a business that is ethical in its dealings;

- $\quad l$ lead to a lower incidence of staff turnover, as well as increased productivity, as employees prefer to work at an ethical organisation;

- $\quad$ easily attract potential employees wanting to work for the organisation, thereby reducing recruitment costs and helping the company get the right skilled people; or

- help to protect the business from a possible hostile takeover by attracting investors and keeping the organisation share price high.

\footnotetext{
${ }^{1}$ Based on the Cadbury Schweppes Corporate and Social Responsibility Report of 2002. Available from: http://businesscasestudies.co.uk/cadbury-schweppes/ethical-business-practices/the-importance-of-ethics-inbusiness.html\#axzz2LFGApZGR
}

$1088 \quad$ Copyright by author(s) $\underline{\text { Creative Commons License CC-BY }}$

2013 The Clute Institute 
Business ethics, as opposed to ethics in general, examines the ethical principles and moral or ethical problems that arise within a business environment. Businesses must adhere to ethical behaviour in their day-to-day operations, as this forms the moral fibre of the organisation (Crystal, 2013:1; Velentzas \& Broni, 2010:795). Pasternak (n.d.:1) defines business ethics as a specialised brand of ethics that focuses on how mental standards apply to business organisations and behaviour. Furthermore, Velentzas and Broni (2010:795) see business ethics as “... the set of moral principles and values that take control over the behaviour of the organisation with reference to what is regarded as right and wrong."

Business ethics is defined by Shakeel, Khan and Khan (2011:59) and Shaw (2002:4) as “... the recognition and implementation of commonly agreed upon standards of conduct that ensures that the company will not impact its stakeholders negatively." In simpler terms, one can see business ethics as what is regarded as right and wrong or good and bad human behaviour in a business setting. What is regarded as right or wrong, otherwise good or bad, will obviously be influenced by various factors such as the type of staff, their cultural background, and so forth, and will differ from company to company. What is needed today is for businesses to be profitable while still conducting business in such a way that it can be seen as ethical.

While ethics dictate the working of a social system, morals define our characteristics (Borade, 2012:1). Ethics point toward the application of morality, while morality is derived from ethics (Borade, 2012:1). The next section will discuss morality, as well as an individual's sense of moral behaviour.

\section{Morality}

The way things are done in organisations, or even in peoples' everyday life, is a result of standards or controls that have been put in place and not really moral behaviour. This may be the way people are expected to dress when going to church or work, or even the way we treat older people. These all commonly assume that an individual's moral sense guides moral behaviour (Krebs, 2011:206). Borade (2012:1) states that while business ethics signifies the abstract moral code accepted and obeyed to by single members of the group or business, morality is the judgements, values and guidelines of good conduct in the community or workplace. Morality is what guides people toward acceptable behaviour, with regards to basic values (Mujtaba, 2005:1).

Morality, according to Borade (2012:1), refers to an adopted code of conduct within an environment and a set of agreed-upon rules for what is right and wrong. Krebs (2011:25) sees morality as the equilibrium of individuals which implies that interaction takes place according to a set of rules that balances the benefits and burdens of cooperation. Morality has become the foundation of all individuals' lives and their consciences and; in a way, morality is in sync with ethics. Morality embraces a person's beliefs about the appropriateness or goodness of what he or she does, thinks or feels (Encyclopǽdia Britannica, n.d.:1).

The next section will discuss some ethical dilemmas that can occur in the business environment, which management and employees should be well aware of as it directly impacts ethics in businesses and the moral issues of individuals.

\section{Ethical Dilemmas/Misconduct in the Small Business Environment}

Ethical or unethical behaviour and judgement usually occur in situations that raise ethical considerations or issues. "An ethical issue is a problem, situation or opportunity requiring an individual or organisation to choose among several actions that must be evaluated as right or wrong, ethical or unethical" (Pasternak, n.d.:5). Ethical issues are equivocal, meaning that they can be interpreted in more than one way and are uncertain with regard to the future. Ethical issues are often problematic as they refer to non-traditional situations - they have not been encountered in the past and do not easily fit into well-used categorisation schemes (Pasternak, n.d.:5). One thing that stands out, however, is the fact that if unethical behaviour is prevalent in a business, it poses a significant risk to the organisation and their stakeholders.

SMEs are the ones that are in a very unfortunate position today regarding corruption, fraud, and other unethical practices. This is due to the fact that, on the one hand, they need to survive and as they tend to be small in 
size, they experience more difficulties. On the other hand, they are aware of large scale of unethical practices taking place in large companies, as well as government, and see this as standard or acceptable practice. This may influence their behaviour and perceptions, and even make them more open to dishonest behaviour. In many instances, these unethical actions will be seen as a need to survive and those same actions from larger corporations will be seen as greed - maybe a form of moral justification. Their size ultimately limits their resources and capabilities to avoid corruption and fraud in the business sector. Consequently, many small businesses accept corruption and fraud as normal, acceptable practices, and utilise it as a means of getting something done quicker, despite knowing it is illegal and unethical (Rune, 2011:1).

There are a number of ethical concerns that have been identified as the most commonly found forms of misconduct in the business environment of which employees and owners should be well aware of (Botha, 2012:610), which include bribery, coercion (or bullying), theft, discrimination, fraud, harassment, dishonest, cover-up, and pornography. Collins (2012:6-7) observed that the most often ethical misconduct experienced by respondents was the abuse of a company's resources, abusive behaviour toward employees, lying to employees, Internet abuse, conflict of interest, discrimination, lying to stakeholders, employee benefit abuse, employee privacy violation, and falsifying expenses. However, these actions of misconduct are not limited to large organisations, but equally apply to small companies in all sectors. In a survey conducted by Collins (2012:6-7) of small business professionals, the major concerns identified regarding ethical behaviour were kickbacks paid to employees, honesty in contracts and internal communications, and the granting of pay raises. By nature of their limited size, small businesses may also be more prone to bullying from a large unethical customer or supplier (Collins, 2012:9). In the next section, the correlation between a sense of moral behaviour (or moral awareness) and concern for ethical behaviour is discussed.

\section{Sense of Moral Behaviour and Concern for Ethical Misconduct}

True and honest ethical behaviour stems from a sense of moral responsibility toward fellow human beings and is not done for self-adoration, but because it is the right thing to do. Moral responsibility is influential as it is compelled by a sense of concern for other people and is done opposed to selfishness (Lawrence, Collins, Pavlovich \& Arunachalam, 2006:252). Due to the inherent nature of people to disobey set rules, morality cannot be based on rules (Lawrence et al., 2006:252).

In the study of Butterfield, Treviño and Weaver (2000:982), the researchers aimed to understand the factors that have an influence on individuals in a business environment and whether they will recognise the moral nature of an uncertain ethical situation. The study found that people are more prone to identify immoral situations if the issue has momentous negative consequences, as opposed to those that are not viewed as having a huge impact or effect (Butterfield et al., 2000:1000). The study also suggests that a perceived social situation will influence the moral awareness and behaviour of individuals and will determine the specific behaviour (Butterfield et al., 2000:1001).

In the current economic climate and the realities faced by small businesses, moral concerns are widespread as there are various conflicting standards and interests due to rare resources, high uncertainty and risk, vague roles, and continuous competitive strain. The most common moral issue that entrepreneurs encounter is deciding between upholding normative business ethics and following their own egotism for their own interest (Bryant, 2009:505). Bryant (2009:505) states that it is evident that employees and managers are ill equipped to cope with ethical challenges due to a variety of reasons and, therefore, they may not even perceive ethical issues in the working environment. In other words, there is a lack of awareness in a moral sense of any problems that may be manifested in the workplace. This lack of moral awareness can have a profound impact on the company, as a person who is unaware of immoral or unethical situations is more likely to not consider moral issues when decisions are made. From a normative perspective, a lack of moral awareness will increase the risk of a person behaving immorally and an increase in business ethics misconduct (Bryant, 2009:505). It can therefore be inferred that moral awareness is the backbone to an individual's sense of moral behaviour and ethical decision-making.

\section{RESEARCH OBJECTIVES}

The main aim of this research study was to determine whether a sense of moral behaviour will have an influence on the concern for ethical misconduct in the Nigerian business environment by examining the relationship between "Moral Behaviour" and the "Concern for Ethical Dilemmas/Misconduct". 
From the literature reviewed, the following research hypothesis was developed:

$\mathbf{H}_{0}$ : Entrepreneurs who have an acute sense of moral behaviour are concerned about ethical misconduct/dilemmas in the business environment.

It is evident that there are various factors that influence the moral behaviour of an individual and that people go through a moral decision-making process to determine whether the situation is right or wrong. The study therefore aims to determine whether an entrepreneur's or owner's sense of moral behaviour would have an effect on their concern for ethical misconduct in the small business environment.

\section{RESEARCH METHODOLOGY}

With the purpose of determining whether an individual's acute sense of moral behaviour will have an effect on their concern towards ethical misconduct in their business environment, the research was conducted using quantitative data, with the data collection instrument being that of a survey questionnaire. In order to determine this relationship, primary data were collected from small Nigerian business entrepreneurs and owners. The sampling methods that were used were that of convenience sampling, and the rationale for choosing this sampling method was that it is the most effective sampling method for collecting data within a short period of time (Zikmund \& Babin, 2007:273). The sample size for the study comprised of 42 Nigerian entrepreneurs, or owners of SME's, who started their own business or are in the process of starting up their own business.

Moral behaviour in the workplace was measured with ten statements to which participants could respond to on a 7-point Likert scale that varied from Strongly Disagree (1) to Strongly Agree (7). An overall mean score for the construct "Moral Behaviour" was determined for each respondent and the variation in perceptions was established. The concern for ethical dilemmas/misconduct was also measured with ten statements on a 7-point Likert scale that varied from Strongly Disagree (1) to Strongly Agree (7). An overall mean score for the construct "Ethical Dilemmas/Misconduct" was determined for each respondent and a variation in these perceptions was established.

Reliability of the above two constructs was established to ensure that the internal consistency by which the statements measured the constructs was adequate.

Several statistical techniques were employed to determine the relationships/associations between the constructs "Moral Behaviour" and "Ethical Dilemmas/Misconduct" and the views of the gravity and impact of unethical behaviour in the workplace. An attempt was also made to determine whether the biographic features of respondents influenced their views.

The biographic profile of respondents is presented in Table 1.

Table 1: Biographic Profile of Respondents

\begin{tabular}{|c|c|c|}
\hline Biographic Feature & $\mathbf{N}$ & $\%$ \\
\hline \multicolumn{3}{|l|}{ Gender } \\
\hline Female & 17 & $42.5 \%$ \\
\hline Male & 23 & $57.5 \%$ \\
\hline Total & 40 & $100.0 \%$ \\
\hline \multicolumn{3}{|l|}{ Age } \\
\hline$<19$ years & 1 & $2.4 \%$ \\
\hline 19- 25 years & 4 & $9.5 \%$ \\
\hline $26-35$ years & 11 & $26.2 \%$ \\
\hline $36-45$ years & 17 & $40.5 \%$ \\
\hline $46-55$ years & 9 & $21.4 \%$ \\
\hline Total & 42 & $100.0 \%$ \\
\hline \multicolumn{3}{|l|}{ Race } \\
\hline Black & 41 & $97.6 \%$ \\
\hline Other & 1 & $2.4 \%$ \\
\hline Total & 42 & $100.0 \%$ \\
\hline
\end{tabular}


The Small Business Enterprise entrepreneurs and/or owners who participated in the survey were mostly in the age category of $19-45$ years $(92.1 \%)$, were male dominated $(57.5 \%)$, and the respondents to the survey were mainly Black entrepreneurs $(97.6 \%)$.

\section{RESEARCH FINDINGS}

\section{Moral Behaviour}

Ten statements were posed in the questionnaire to solicit the participants' response on a 7-point Likert scale on "Moral Behaviour" in the workplace. This is a very useful question type when it is required to get an overall measurement of a particular topic, opinion, or experience and also to collect specific data on contributing factors.

To ensure that the statements Q2.1 to Q2.10 of the questionnaire are related in the measurement of the topic, an item analysis had to be performed. The sample size to perform this analysis, however, requires a minimum of 70 respondents (the product of the scale size and the number of items of this theme). Given the size of the sample, it was necessary to collapse the Likert scale to a 3-point scale. This was achieved by recoding the three negative perceptions to a single negative view (disagree) and the three positive perceptions to a single positive view (agree). The "neutral" or "don't know" view remained unchanged. Note that a collapse in scale will result in a loss of information. Behaviour".

Table 2 presents the distribution of responses to each of the ten statements on the construct/topic "Moral

Table 2: Distribution of Responses - "Moral Behaviour"

\begin{tabular}{|c|c|c|c|}
\hline Label & $\begin{array}{c}\% \\
\text { Disagree }\end{array}$ & $\begin{array}{c}\% \\
\text { Neutral } \\
\end{array}$ & $\begin{array}{c}\% \\
\text { Agree }\end{array}$ \\
\hline 2.1 People should make sure their actions never harm others, even to a small degree. & $28.6 \%$ & $4.8 \%$ & $66.7 \%$ \\
\hline 2.2 Risk to others should never be tolerated, irrespective of how small the risk might be. & $31.7 \%$ & $9.8 \%$ & $58.5 \%$ \\
\hline 2.3 One should never psychologically or physically harm others. & $11.9 \%$ & $11.9 \%$ & $76.2 \%$ \\
\hline 2.4 If an action could harm an innocent person, then it should not b & $14.3 \%$ & $14.3 \%$ & $71.4 \%$ \\
\hline $\begin{array}{l}2.5 \text { The dignity and welfare of the people should be the least important concern in any } \\
\text { society. }\end{array}$ & $64.3 \%$ & $11.9 \%$ & $23.8 \%$ \\
\hline $2.6 \mathrm{It}$ is necessary to sacrifice the dignity of others. & $52.4 \%$ & $11.9 \%$ & $35.7 \%$ \\
\hline 2.7 Different types of morality cannot be compared to "righteousness." & $26.2 \%$ & $19.0 \%$ & $54.8 \%$ \\
\hline 2.8 Moral behaviour is actions that closely match ideas of the most perfect action. & $17.1 \%$ & $14.6 \%$ & $68.3 \%$ \\
\hline $\begin{array}{l}2.9 \text { Whether a lie judged to be moral or immoral, depends on the circumstances surrounding } \\
\text { the action. }\end{array}$ & $25.0 \%$ & $20.0 \%$ & $55.0 \%$ \\
\hline 2.10 What is ethical varies from one situation and society to anoth & $19.0 \%$ & $11.9 \%$ & $69.0 \%$ \\
\hline
\end{tabular}

Figure 1 is a visual presentation of the relative density of responses.

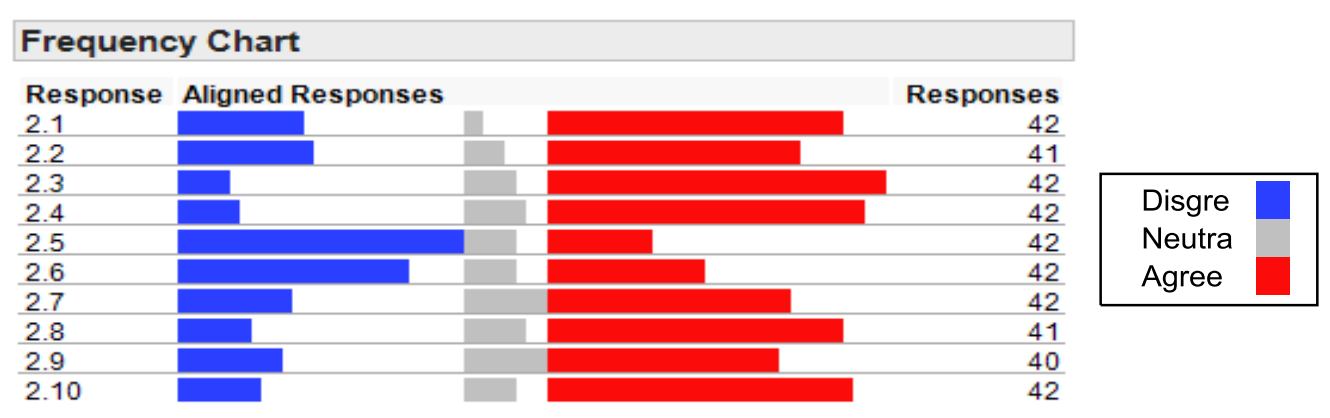

Figure 1: Density of Respondents' Perception towards "Moral Behaviours" 
In general, there is a predominance to the agree side of the scale, except for Q2.5 (The dignity and welfare of the people should be the least important concern in any society) and Q2.6 (It is necessary to sacrifice the dignity of others).

To establish whether the ten Likert items of the theme or construct "Moral Behaviour" are related, an item analysis was performed. An item (or reliability) analysis is a statistical technique which determines the internal consistency of the items that constitute the construct. Cronbach's alpha value, which varies from 0 to 1 , is one measure for determining this consistency. A Cronbach's alpha value between 0.6 and 0.8 is regarded as adequate, while a value $>0.8$ is considered as good internal consistency and an alpha value $<0.6$ is considered to be unacceptable.

An initial overall Cronbach's alpha value of 0.7348 was recorded for the ten Likert items. However, very low and even negative correlations existed between Q2.5 and Q2.6 and the other items of this theme. This was to be expected with the inspection of the table of distributions above. Removal of these two items yielded an improved alpha value of 0.749 . This alpha value represents acceptable consistency and relationship between the items. An overall theme or construct could therefore be represented by the ten items.

The overall score for the theme "Moral Behaviour" is represented by a single value by calculating the mean response for each respondent for the ten statements.

Table 3 and Figure 2 provide descriptive statistics and a distribution of respondents mean score for this construct.

Table 3: Descriptive Statistics and Distribution of Respondents for "Moral Behaviour"

\begin{tabular}{|l|c|}
\hline Mean & 2.436 \\
\hline Std. Dev. & 0.4949 \\
\hline Std. Err. Mean & 0.0763 \\
\hline Upper 95\% Mean & 2.591 \\
\hline Lower 95\% Mean & 2.282 \\
\hline N & 42 \\
\hline
\end{tabular}

The mean score for the construct "Moral Behaviour" is 2.47 (on a scale of 1 to 3) with a $95 \%$ confidence interval of $2.28-2.59$. This has already been seen, from the distribution and density table and chart above, as predominantly positive.

A distribution of these scores was investigated for normality to determine whether parametric statistical techniques could be employed. Most parametric techniques demand at least normally distributed data, homogenous variances when comparing groups, as well as independence.

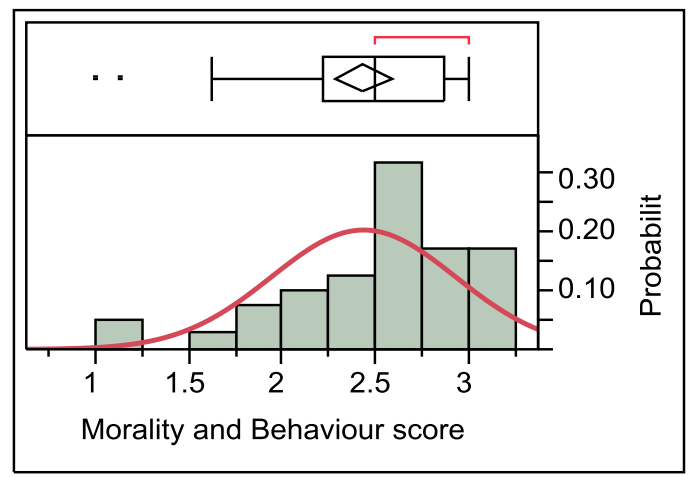

Figure 2: Distribution of the Mean Score for "Moral Behaviour"

The mean score recorded for the theme "Moral Behaviour" is skewed to the right. A normality test, using the Shapiro-Wilk test, was conducted with acceptance of normality at the 0.01 level of significance. 


\section{Concern for Ethical Dilemmas/Misconduct}

The ten statements or Likert items of the proposed construct "Concern for Ethical Dilemmas/Misconduct" were also posed to the participants in the survey.

To ensure that the statements Q3.1 to Q3.10 of the questionnaire are related in the measurement of the topic, an item analysis had to be performed. The sample size to perform this analysis, however, requires a minimum of 70 respondents (the product of the scale size and the number of items of this theme). Given the size of the sample, it was necessary to collapse the Likert scale to a 3-point scale. This was achieved by recoding the three negative perceptions to a single negative view (disagree) and the three positive perceptions to a single positive view (agree). The neutral or view remained unchanged. Note that a collapse in scale will result in a loss of information.

Table 4 summarises the "Concern for Ethical Dilemmas/Misconduct".

Table 4: Concern for Ethical Dilemmas/Misconduct

\begin{tabular}{|l|c|c|c|}
\hline \multicolumn{1}{|c|}{ Concern } & \% Disagree & \% Neutral & \% Agree \\
\hline 3.1 Dishonesty & $39.0 \%$ & $2.4 \%$ & $58.5 \%$ \\
\hline 3.2 Fraud & $32.5 \%$ & $5.0 \%$ & $62.5 \%$ \\
\hline 3.3 Cover-up & $34.1 \%$ & $12.2 \%$ & $53.7 \%$ \\
\hline 3.4 Discrimination & $36.6 \%$ & $7.3 \%$ & $56.1 \%$ \\
\hline 3.5 Promise keeping & $41.5 \%$ & $2.4 \%$ & $56.1 \%$ \\
\hline 3.6 Bullying & $39.0 \%$ & $2.4 \%$ & $58.5 \%$ \\
\hline 3.7 Bribery & $34.1 \%$ & $2.4 \%$ & $63.4 \%$ \\
\hline 3.8 Pornography & $37.5 \%$ & $15.0 \%$ & $47.5 \%$ \\
\hline 3.9 Theft & $31.7 \%$ & $7.3 \%$ & $61.0 \%$ \\
\hline 3.10 Harassment & $39.0 \%$ & $0.0 \%$ & $61.0 \%$ \\
\hline
\end{tabular}

Figure 3 represents the relative density of responses.

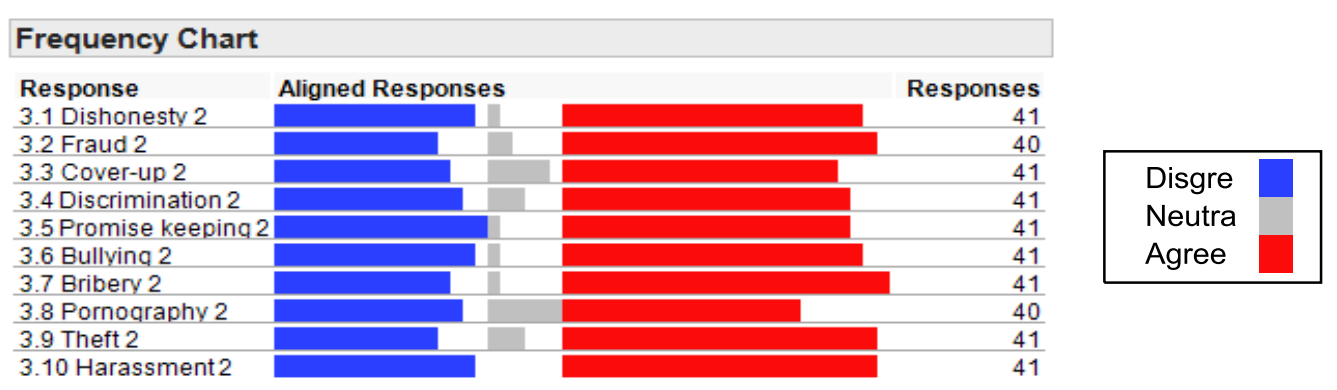

Figure 3: Respondent Density Chart - "Concern for Ethical Dilemmas/Misconduct"

From the table and figure above, there appears to be a predominance toward the agree side of the Likert scale. An item (or reliability) analysis was performed upon the ten items (or statements) of the theme or construct "Concern for Ethical Dilemmas/Misconduct" to ensure that the items are related.

An overall Cronbach's alpha value of 0.973 was recorded for nine Likert items. Item 3.5 (Promise keeping) had a very low and even negative correlation with the other items of this theme and the removal of the item improved the alpha value from 0.934 to 0.973 .

The theme or construct "Concern for Ethical Dilemmas/Misconduct" in the workplace could reliably be measured by a single value by calculating the mean response for each respondent from the ten items. 
Table 5 and Figure 4 provide descriptive statistics and a distribution of respondents of the overall mean score for this construct.

Table 5: Descriptive Statistics and Distribution of Respondents for "Concern for Ethical Dilemmas/Misconduct"

\begin{tabular}{|l|c|}
\hline Mean & 2.221 \\
\hline Std. Dev. & 0.8218 \\
\hline Std. Err. Mean & 0.1283 \\
\hline Upper 95\% Mean & 2.480 \\
\hline Lower 95\% Mean & 1.961 \\
\hline N & 41 \\
\hline
\end{tabular}

A mean score of 2.22 was determined for the construct "Concern for Ethical Dilemmas/Misconduct" with a $95 \%$ interval for the mean of $1.96-2.96$.

\section{Concern for Ethical Dilemmas/Misconduct}

Figure 4 illustrates the mean scores distribution of the "Concern for Ethical Dilemmas/Misconduct".

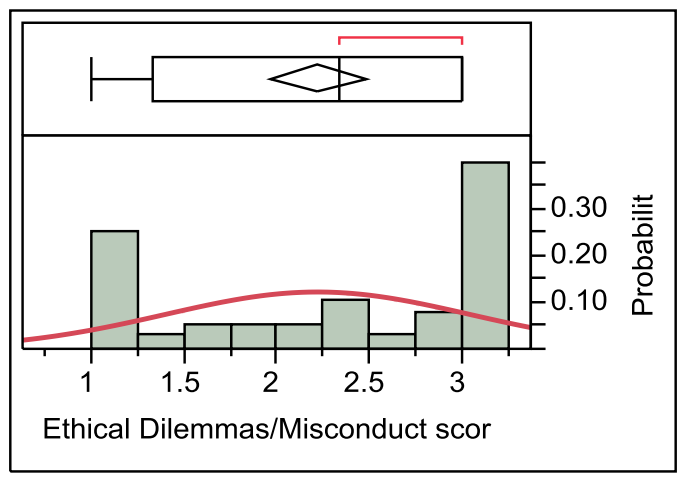

Figure 4: Distribution of Mean Scores - "Concern for Ethical Dilemmas/Misconduct"

The above histogram presents the distribution of the mean scores of the individual responses for the construct "Concern for Ethical Dilemmas/Misconduct." This distribution is decidedly non-normal, as also indicated by the Shapiro-Wilk normality test.

\section{Relationship between Concern for Ethical Dilemmas/Misconduct in the Workplace and Moral Behaviour}

Since both "Moral Behaviour" and "Concern for Ethical Dilemmas/Misconduct" in the workplace are continuous variables, the strength of the linear relationship between these constructs could be measured. This was achieved through a correlation coefficient and a linear fit between the two variables.

Table 6 summarises the multivariate correlations of "Moral Behaviour" and "Concern for Ethical Dilemmas/Misconduct".

Table 6: Multivariate Correlations of "Moral Behaviour" and "Concern for Ethical Dilemmas/ Misconduct"

\begin{tabular}{|l|c|c|}
\hline \multicolumn{3}{|c|}{ Multivariate Correlations } \\
\hline & Moral Behaviour & Ethical Dilemmas/Misconduct \\
\hline Moral Behaviour & 1 & 0.5132 \\
\hline Ethical Dilemmas/Misconduct & 0.5132 & 1 \\
\hline
\end{tabular}


The correlation of 0.513 indicates that there is a positive medium correlation between "Moral Behaviour" and "Concern for Ethical Dilemmas/Misconduct". Figure 5 provides a visual view of the linear relationship.

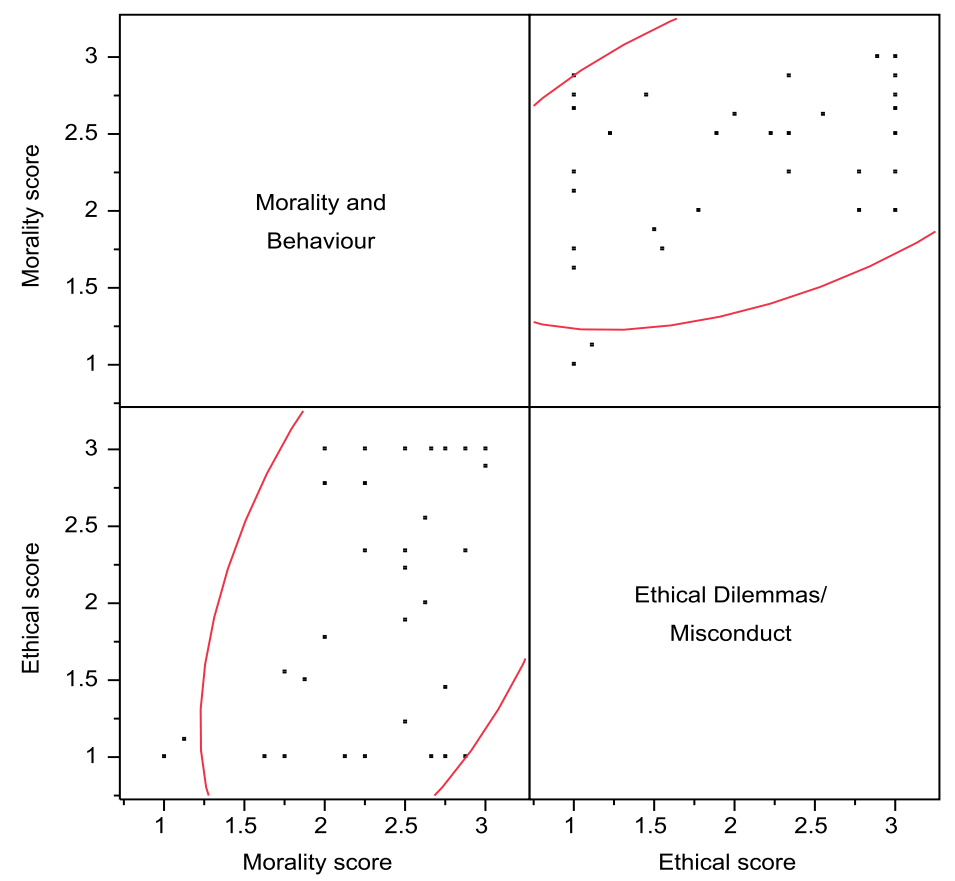

Figure 5: Scatter Plot Matrix: "Moral Behaviour" and "Concern for Ethical Dilemmas/ Misconduct"

However, a bivariate density plot of these constructs reveals a distinct group of outliers in this linear presentation, which is illustrated in Figure 6.

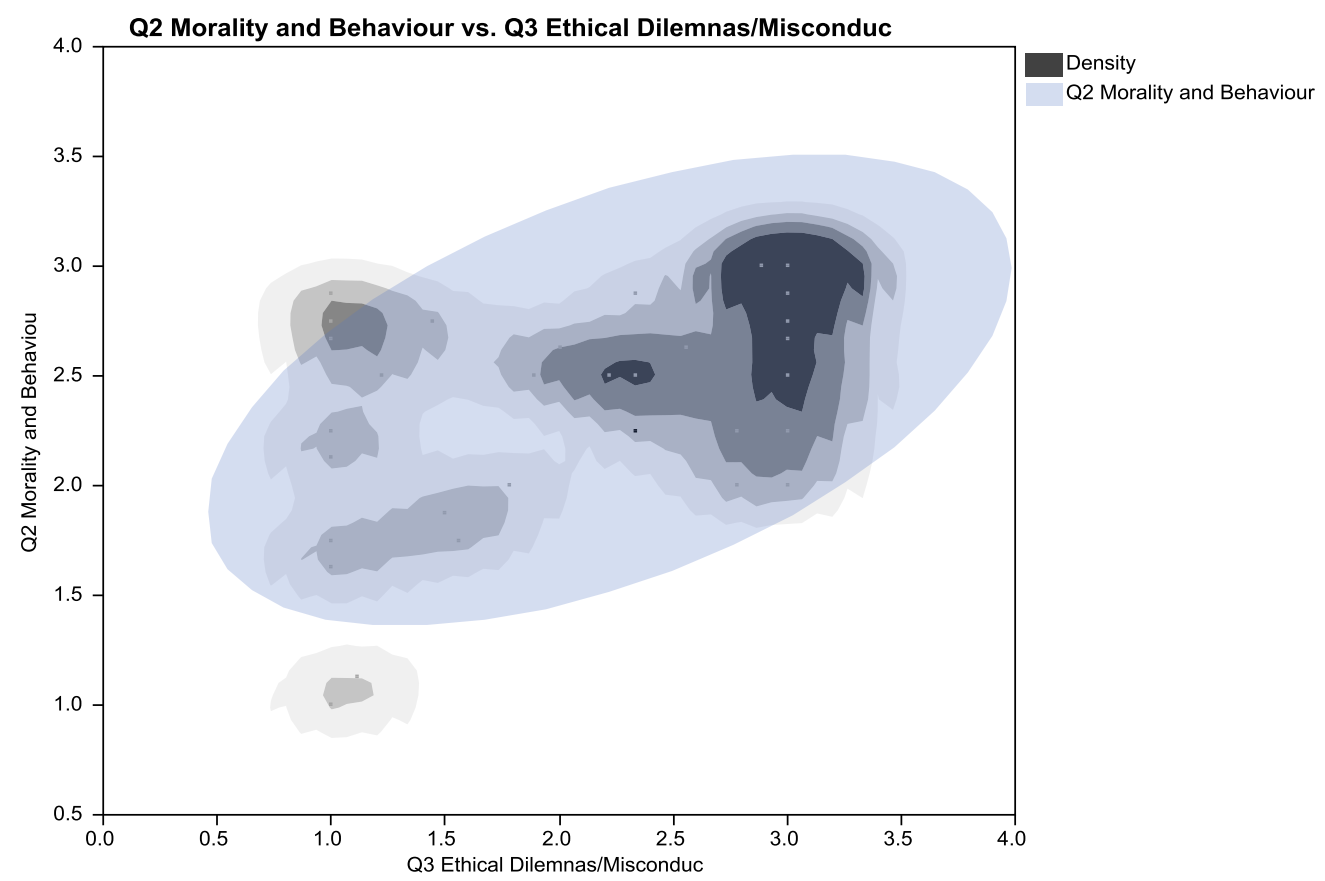

Figure 6: Density Plot - Bivariate Fit of "Moral Behaviour” by 'Concern for Ethical Dilemmas/ Misconduct” 
It is considered (or rather speculated) that the three outlying values, displayed in the top left-hand corner, result from owners who do not share the same concern for ethical misconduct in the workplace, but still display high moral standards. This may be attributed to family businesses where greater homogeneity in purpose and personal values exist.

The extent of this linear relationship (without the three outlying values) is presented with the following correlation matrix (Table 7) and associated scatter plot (Figure 7).

Table 7: Multivariate Correlations - "Moral Behaviour" and "Concern for Ethical Dilemmas/ Misconduct"

\begin{tabular}{|l|c|c|}
\hline \multicolumn{3}{|c|}{ Multivariate Correlations } \\
\hline & Moral Behaviour & Ethical Dilemmas/Misconduct \\
\hline Morality and Behaviour & 1 & 0.6662 \\
\hline Ethical Dilemmas/Misconduct & 0.6662 & 1 \\
\hline
\end{tabular}

Figure 7 illustrates the correlation matrix of the relationship between "Moral Behaviour" and "Concern for Ethical Dilemmas/Misconduct" in the form of a scatter plot.

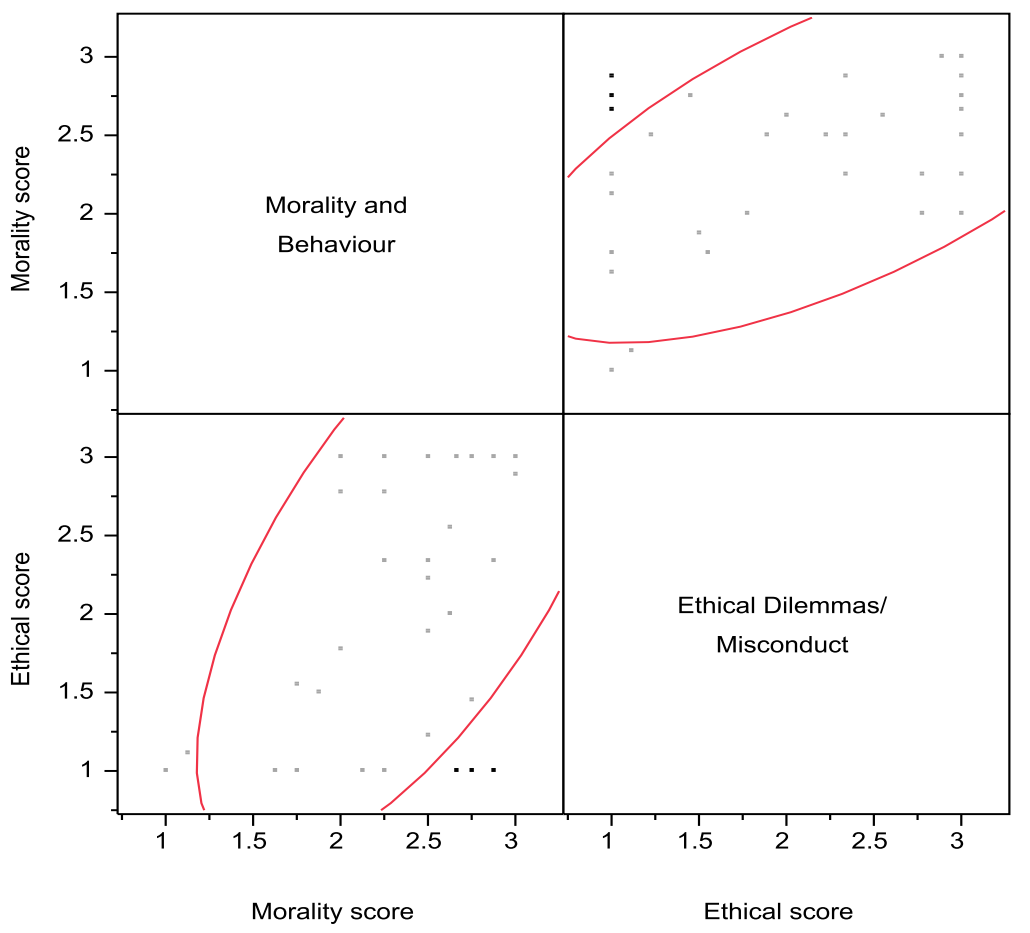

Figure 7: Scatter Plot Matrix - "Moral Behaviour" and "Concern for Ethical Dilemmas/Misconduct"

With the exclusion of the three outlying values, the positive linear correlation has improved from 0.5132 - a medium correlation - to 0.6662 which represents a medium to strong correlation.

The relationship between these two constructs is formalised in a best linear fit between "Concern for Ethical Dilemmas/Misconduct" in the workplace and "Moral Behaviour". The best fit is the minimum deviation between the actual values and the predicted line.

The straight line fit below the coefficient of determination (also denoted $\mathrm{R}^{2}$ ) is a measure of goodness of the best fit. The $\mathrm{R}^{2}$ coefficient is also a measure of accuracy in predicting future outcomes. In the model below, an $\mathrm{R}^{2}$ value of 0.45 was recorded, indicating a $45 \%$ accuracy in predicting "Moral Behaviour" given "Concern for Ethical Dilemmas/Misconduct" in the workplace. 
In regression, Analysis of Variance (ANOVA) consists of calculations that provide information about levels of variability within a regression model and form a basis for tests of significance. In this model, a F statistics (or ratio) of $F_{1,36}=29.47$ was recorded with an accompanying significance level $<0.0001$. This indicates that the model below is significant at the $99 \%$ level of significance.

Model parameter estimates are as follows:

- $\quad$ Intercept $=1.3829$ with a t-ratio $=6.95$ and an accompanying significance value of 0.0001 .

- Concern for Ethical Dilemmas and Misconduct in the workplace $=0.4428$ with a t-ratio $=5.43$ and an accompanying significance value $<0.0001$. The estimates of the parameters are therefore significant at the 99\% level of significance.

The prediction model derived is thus: Moral Behaviour $=1.3829+0.4428 *$ Ethical Dilemmas/Misconduct

The bivariate fit of "Moral Behaviour" by "Concern for Ethical Dilemmas/Misconduct" is graphically portrayed in Figure 8.

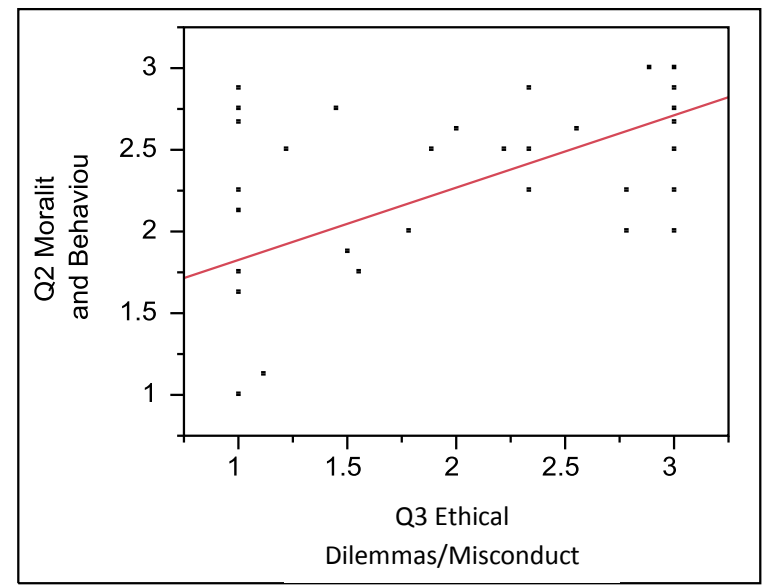

Figure 8: Bivariate Fit of "Moral Behaviour" by "Concern for Ethical Dilemmas/Misconduct"

It can thus be generalised that an increase in the score for "Concern for Ethical Dilemmas/Misconduct" is accompanied by an increase in the score for "Moral Behaviour."

\section{CONCLUSION}

The focus of this research is to determine whether a sense of moral behaviour will have an influence on the concern for ethical misconduct in the Nigerian small business environment. Ethics and morals are two terms used interchangeably; although closely related, there is a clear distinction. Ethics refers to series of rules and principles used to decide what behaviours are right, good, and proper. It defines how things should work according to rules of conduct, prescribed to an individual by an external source such as a profession, business, and social system. Business ethics is therefore the rules and principles prescribed by businesses and must be consistent with the business environment. However, morality refers to the accepted standards of behaviour within society. It defines how things should work according to an individual's own beliefs and principles regarding right and wrong. It is clear from the literature that it is all about rules and actions.

This study reveals that various behavioural aspects (moral issues) can be clustered as a single construct or theme "Moral Behaviour". The consistency and relationship between the items yield a Cronbach alpha of 0.749. It is also clear that ethical issues can be clustered into a single theme - "Ethical Dilemmas/Misconduct". The consistency and relationship between the "Ethical Dilemmas/Misconduct" items yield a Cronbach alpha of 0.973. 
The study confirms that there is a medium to strong relationship correlation between sense of ethical concerns and immoral behaviour in the Nigerian small business environment. The analysis produces a correlation coefficient of 0.6662 . The hypotheses $\left(\mathrm{H}_{0}\right.$ : Entrepreneurs who have an acute sense of moral behaviour are concerned about ethical misconduct and dilemmas in the business environment) is therefore accepted. It is clear from the results that age, gender, and race do not have an influence on Nigerian SME business entrepreneurs' view of "Moral Behaviour" or "Concern for Ethical Dilemmas/Misconduct" in the workplace.

As ethical dilemmas include acts of dishonesty, fraud, cover-up, discrimination, promise keeping, bullying, bribery, pornography, theft, and harassment, it can negatively impact on a small business if a member of the staff makes him or herself accountable to acts of ethical misconduct due to peer and societal disapproval. It is recommended that Nigerian small business entrepreneurs or owners scrutinise ethical dilemmas during staff interviews, provide training in ethical issues, and have policies and procedures in place for dealing with ethical misconduct once it occurs in the workplace, as an ethical employee will not accept a bribe, but an immoral employee would.

\section{AUTHOR INFORMATION}

Prof. Johannes A. Wiid is a senior lecturer in the Department of Marketing and Retail Management at the University of South Africa (UNISA). He has published various articles in refereed journals and is the editor and author of more than 5 books in marketing. These books are widely prescribed at universities in South Africa. He holds a DCom in Marketing from the University of Johannesburg. E-mail: jwiid@unisa.ac.za (Corresponding author)

Prof Michael C. Cant is the Head of the Department of Marketing and Retail Management at the University of South Africa (UNISA). He has published over 40 articles in refereed journals and is the editor and author of more than 30 books in marketing. These books are widely prescribed at universities in South Africa. He has presented papers at more than 45 international conferences all over the world and is a well respected marketing and retail scholar. He holds a DCom in Marketing from the University of South Africa. E-mail: cantmc@unisa.ac.za

Ms. Claudette van Niekerk is an Academic Research Assistant in the Department of Marketing and Retail Management at the University of South Africa (UNISA). She has contributed towards the writing of articles and prescribed textbooks in the field of marketing and is currently in the process of completing her MCom in Business Management with specialisation in Marketing and Retail Management from UNISA. E-mail: vniekc@unisa.ac.za

\section{REFERENCES}

1. Borade, G. (2012). Difference between ethics and morality. Retrieved from: http://www.buzzle.com/articles/difference-between-ethics-and-morality.html

2. Botha, H.J. (2012). Investigating the ethical considerations faced by small business entrepreneurs in the informal sector: Zandspruit Township, Johannesburg. Retrieved from: http://www.uj.ac.za/EN/Faculties/management/departments/CSBD/Documents/2010\%20CSBD\%20Confer ence\%20Docs/BS Botha.pdf

3. Bryant, P. (2009). Self-regulation and moral awareness among entrepreneurs. Journal of Business Venturing, 24(5): 505-518. Retrieved from: http://dx.doi.org/10.1016/j.jbusvent.2008.04.005 [Downloaded: 2013-02-21].

4. Butterfield, K.D. Treviño, L.K \& Weaver, G.R. (2000). Moral awareness in business organisations: influences of issue-related and social context factors. Human Relations, 53(7): 981-1081. Retrieved from: http://www.personal.psu.edu/krm10/ PSY597SP07/Butterfield\%20moral.pdf

5. $\quad$ Collins, D. (2012). Business ethics: how to design and manage ethical organisations. USA: Wiley.

6. Crystal, G.( 2013). Business ethics. Retrieved from: http://www.wisegeek.org/what-is-business-ethics.htm

7. Daveninderak, K. (2009). The relationship between organisational ethics and job satisfaction: a study of managers in Malaysia. Retrieved from: http://dspace.fsktm.um.edu.my/bitstream/1812/585/1/Org\%20Ethics\%20\%26\%20job\%20satisfaction\%20\%20Research\%20Project\%202.7.09.pdf 
8. Encyclopaedia Britannica. n.d. Human behaviour. Retrieved from: http://global.britannica.com/EBchecked/topic/275332/human-behaviour/24935/A-moral-sense

9. $\quad$ Krebs, D.L. (2008). Morality: An evolutionary account. Retrieved from: http://www.sfu.ca/psyc/faculty/krebs/publications/Morality.\%20An\%20evolutionary\%20account.pdf

10. Krebs, D.L. (2011). The Origins of Morality: An evolutionary account. New York: Oxford University Press. Retrieved from: http://books.google.co.za/books?id=wpeKkhkGe0C\&pg=PA206\&dq=sense+of+moral+behaviour\&hl=en\&sa=X\&ei=Vu0hUZjTJ8qXhQen2ICoAw\&ve $\mathrm{d}=0 \mathrm{CC} 8 \mathrm{Q} 6 \mathrm{AEwAA \#} \mathrm{v}=$ onepage $\& \mathrm{q}=$ sense $\% 20$ of $\% 20$ moral\%20behaviour $\& \mathrm{f}=$ false

11. Lawrence, S.R., Collins, E., Pavlovich, K. \& Arunachalam, M. (2006). Sustainability practices of SMEs: the case of NZ. Business strategy and the environment, 15(4):242-257. Retrieved from: http://dx.doi.org/10.1002/bse.533

12. Mahdavi, I.(2009). International business ethics: strategies and responsibilities. Journal of Academic \& Business Ethics, 2(Jul):1-6.

13. Mujtaba, B. (2005). Understanding ethics and morality in business. Retrieved from: http://www.sbnonline.com/2005/04/understanding-ethics-and-morality-in-business-there-are-distinctdifferences-between-ethics-and-morality/

14. Ogundele, O.J.K. Hassen, A.R. Idris, A.A. Adebakin, M.A \& Iyiegbuniwe, P.I. (2010). Challenges of ethics in Nigeria within the context of global ethical practices. Retrieved from: http://www.google.co.za/url?sa=t\&rct=j\&q=\&esrc=s\&frm=1\&source=web\&cd=1\&ved=0CC8QFjAA\&url $=$ http $\% 3 \mathrm{~A} \% 2 \mathrm{~F} \% 2 \mathrm{Fwww}$. unilag.edu.ng\%2Fopendoc.php\%3Fsno\%3D16627\%26doctype \%3Ddoc\%26docn ame\%3D\%24\&ei=ijUrUbCcHYzhAfF34DgAg\&usg=AFQjCNF3akJXDt nFIUfi2oeHnzmQkelGA\&sig2= PZxvVS0ZhXqZnk1h6VbDQg\&bvm=bv.42768644,d.ZG4

15. Okafor, G.O. (2011). The ethical behaviour of Nigerian business students (A study of undergraduate students' in business schools). Arabian Journal of Business and Management Review, 1(3):33-44. Retrieved from: http://arabianjbmr.com/pdfs/om_vol_1_(3)/4.pdf

16. Onugu, B.A.N. (2005). Small and medium enterprises (SMEs) in Nigeria: problems and prospects. Retrieved from: http://www.efiko.org/material/Small\%20and\%20Medium\%20Enterprises\%20(SMEs)\%20in\%20Nigeria$\% 20$ Problems $\% 20$ and $\% 20$ Prospects $\% 20 \mathrm{By} \% 20 \mathrm{Basil} \% 20$ Anthony $\% 20 \mathrm{Ngwu} . \mathrm{pdf}$

17. Pasternak, S. n.d. The role of ethical theories in ethical reasoning and behaviour within organisations. Retrieved from: http://www.ti-israel.org/_Uploads/ dbsAttachedFiles/sigalitpasternak.pdf

18. Paxton, J.M \& Greene, J.D. (2010). Moral reasoning: hints and allegations. Retrieved from: http://dx.doi.org/10.1111/j.1756-8765.2010.01096.x

19. Prinz, J.J. n.d. Is morality innate? Retrieved from: http://subcortex.com/MoralityInnatePrinz.pdf

20. Raisner, J.A. (1997). Using the "ethical environment" paradigm to teach business ethics: the case of the Maquiladoras. Journal of Business Ethics, 16(14):119-127.

21. Riley, J. (2012). Introduction to business ethics. Retrieved from: http://www.tutor2u.net/business/strategy/business-ethics-introduction.html

22. Rune, A. (2011). Corruption and SMEs: Exploring the business case for western SMEs to counter involvement in administrative corruption in developing countries. Retrieved from: http://studenttheses.cbs.dk/bitstream/handle/10417/2807/ anders_rune.pdf?sequence=1

23. Shakeel, M. Khan, M.M \& Khan, M.A.( 2011). Impact of culture on business ethics. Far East Journal of Psychology and Business, 3(2):59-70.

24. Shaw, W.H. (2002). Business ethics. 4th ed. USA: Wadsworth.

25. Valadez, R.M. (2011). The value proposition of small businesses: economic engines for job creation. Journal of Management and Marketing Research, 9:1-11.

26. Velentzas, J \& Broni, G. (2010). Ethical dimensions in the conduct of business: business ethics, corporate social responsibility and the law. The "ethics in business" as a sense of business ethics. International Conference on Applied Economics - IXOAE 2010. Retrieved from: http://kastoria.teikoz.gr/icoae2/wordpress/wp-content/uploads/ articles/2011/10/092.pdf

27. Yang, T. (2006). Towards an egalitarian global environmental ethics. Retrieved from: http://publishing.unesco.org/chapters/978-92-3-104039-9.pdf

28. Zikmund, W.G \& Babin, B.J. 2007. Essentials of marketing research. 3rd ed. USA: Thomson. 